\title{
EFFICACY OF ENDOVENTRICULAR PATCH PLASTY IN LARGE POSTINFARCTION AKINETIC SCAR AND SEVERE LEFT VENTRICULAR DYSFUNCTION: COMPARISON WITH A SERIES OF LARGE DYSKINETIC SCARS
}

\author{
V. Dor, $\mathrm{MD}^{\mathrm{a}}$ \\ M. Sabatier, MD \\ M. Di Donato, $\mathrm{MD}^{\mathrm{b}}$ \\ F. Montiglio, $\mathrm{MD}^{\mathrm{a}}$ \\ A. Toso, $\mathrm{MD}^{\mathrm{b}}$ \\ M. Maioli, $\mathrm{MD}^{\mathrm{b}}$
}

\begin{abstract}
Background: Many believe that dyskinesia is the only predictor of favorable surgical outcome after large myocardial infarction and that akinetic scars do not recover well in patients with globally depressed ventricular function. Methods: This study evaluates clinical and hemodynamic results of endoventricular circular patch plasty in patients with either large akinetic scar $(n=51)$ or large dyskinetic $\operatorname{scar}(n=49)$ and depressed left ventricular function (ejection fraction $<30 \%$ ). Groups were comparable for symptoms, indication for operation, and delay from myocardial infarction. Heart failure was a major indication for operation in both groups. Coronary grafting was performed in $98 \%$ of patients: 10 had mitral valve repair or replacement, and 47 patients with preoperative ventricular arrhythmias had cryotherapy. In-hospital mortality was $12 \%$ (five patients in the akinetic group [10\%] and seven in the dyskinetic group [14\%]). Results: Results showed an early and late improvement in New York Heart Association functional class and ejection fraction (from 23\% $\pm 5 \%$ to $31 \%$ $\pm 11 \%$ to $40 \% \pm 13 \%$ in akinetic patients and from $23 \% \pm 6 \%$ to $41 \% \pm$ $10 \%$ to $41 \% \pm 12 \%$ in dyskinetic patients). Ventricular tachycardia was reduced significantly in both groups early and late after the operation. Conclusion: We conclude that in patients with either large akinetic or dyskinetic scar and severe left ventricular dysfunction, endoventricular circular patch plasty associated with coronary grafting and cryotherapy, when indicated, provides surviving patients with significant improvement in cardiac function. This approach can be considered as an alternative to heart transplantation in patients with severe left ventricular dysfunction. (J Thorac Cardiovasc Surg 1998;116:50-9)
\end{abstract}

arge anterior transmural myocardial infarction Lcauses both early and late distortion of the structure of the heart. The adverse shape raises wall tension and produces mechanical disadvantages and adverse remodeling. ${ }^{1}$ Most postinfarction left ventricular (LV) scar involves the nonresectable septum; this scar may result in an akinetic region or

From the Centre Cardiothoracique de Monaco, Monaco, ${ }^{\mathrm{a}}$ and the Department of Cardiology, University of Florence, Florence, Italy. ${ }^{\mathrm{b}}$

Read at the Seventy-seventh Annual Meeting of The American Association for Thoracic Surgery, Washington, D.C., May 4-7, 1997.

Received for publication May 12, 1997; revisions requested July 15, 1997; accepted for publication March 16, 1998.

Address for reprints: Centre Cardiothoracique de Monaco, 11 Bis Av. D’Ostende, 98400 Monaco Cedex.

Copyright (C) 1998 by Mosby, Inc.

$0022-5223 / 98 \$ 5.00+0 \quad \mathbf{1 2 / 6 / 9 0 3 2 8}$ occasionally in a dyskinetic scar if there is no reperfusion. The segments are asynergic, do not contract to support cardiac output, and may cause chronic heart failure, because remote nonischemic muscle may reduce the ejection fraction (EF) over the years. Dyskinetic aneurysms are rare because thrombolysis or percutaneous transluminal coronary angioplasty during infarction may salvage epicardial muscle and produce an akinetic segment. Conversely, dyskinesia is considered the only predictor of favorable outcome. We have repaired both akinetic and aneurysmal (dyskinetic) segments with endoventricular circular patch plasty (EVCPP). This technique restores circular ventricular architecture by excluding the septal scar and, by means of the Laplace relationship, reducing the cavity to restore wall tension toward normal and thereby improve hemodynamic status. ${ }^{2-5}$

The large, akinetic, poorly demarcated muscle 
with depressed function is more difficult to treat surgically because the differentiation between scar and sound tissue is less evident than in the classic dyskinetic aneurysm. The previous surgical method of linear aneurysmectomy with septal inclusion produces higher mortality and less functional improvement. ${ }^{6}$ Our approach of EVCPP excludes the septum for postinfarction anterior scar. We deal with the extent of asynergy (noncontracting muscle), rather than the presence or absence of dyskinesia, ${ }^{7}$ and improve outcome in patients with low EF. ${ }^{8}$

This study compares clinical and hemodynamic results of EVCPP in patients with depressed function $(\mathrm{EF}<30 \%)$ with either large akinetic postinfarction scar or dyskinetic scar (a recognized aneurysm). In each instance we assessed preoperative regional and global ventricular function by applying the centerline $\operatorname{method}^{9}$ to the angiographic ventricular silhouettes to allow clear distinction between akinesia and dyskinesia and precise early and late follow-up.

\section{Methods}

Patient selection. A retrospective review was carried out on 562 patients who underwent EVCPP repair from May 1987 through March 1996. Clinical and hemodynamic data have been prospectively collected on a computerized database at the Cardiothoracic Center of Monaco since 1987.

The only patients selected were 100 individuals, each of whom had (1) anterior myocardial infarction, (2) preoperative EF of $30 \%$ or less, (3) preoperative quantitative analysis of regional wall motion performed with the centerline method to allow clear distinction between akinesia and dyskinesia, and (4) early postoperative hemodynamic study in each surviving patient.

Hemodynamic, ventriculographic, and electrophysiologic study. Regional wall motion abnormalities were defined as "dyskinetic" (Fig. 1, $A$ ) if absolute motion of contiguous chords is less than zero and "akinetic" (Fig. 1, $B$ ) if equal to zero by the centerline method. The extent of noncontracting muscle or asynergy (A\%) was calculated as the percent length of LV perimeter showing a fractional shortening below 2 standard deviations from normal mean values. This analysis allowed classification of 49 patients with dyskinetic and 51 with akinetic scar. All had an $\mathrm{A} \%$ of $60 \%$ or more and underwent right and left heart catheterization and angiography. Drugs were discontinued before the hemodynamic study unless contraindicated by clinical conditions. Cardiac output was calculated by the thermodilution method, ventricular volumes were measured by the Chapman method, ${ }^{10}$ and contractile EF was determined by the method described by Louagie. ${ }^{11}$ In preoperative coronary arteriograms, the extent and severity of coronary disease (jeopardy score) were evaluated according to the method of Califf and associates. ${ }^{12}$
Sixty-seven patients had a preoperative electrophysiologic study to evaluate inducible ventricular tachycardia. Our protocol, described previously, ${ }^{13}$ included ventricular pacing up to 200 beats/min at the right ventricular apex and one or two extrastimuli at two basic cycle lengths (500 and $600 \mathrm{msec}$ ). We did not do electrophysiologic studies in patients with extremely depressed pump function, left main disease, and intraventricular thrombi owing to the risk of possible hemodynamic deterioration or systemic embolization. All surviving patients had early postoperative hemodynamic study (right and left heart catheterization); postoperative electrophysiologic study was performed in 71 patients in the early postoperative period and 44 patients after 1 year with the identical protocol. Forty-nine patients had late hemodynamic study 1 year after the operation. Clinical follow-up was done by clinical examination or telephone interview.

Surgical technique. The technique has been described previously $^{2,3}$ and is shown in Fig. 2. Procedures are performed with crystalloid cardioplegia (10 patients) or cold blood cardioplegia (90 patients). For coronary revascularization, the internal thoracic artery is grafted to the left anterior descending artery, followed by additional arterial or venous grafting to the right and/or circumflex arteries. The LV is then opened in the center of the depressed anterior area, produced by aspirating the vent catheter (Fig. 2, a). Clots, if present, are removed. In akinetic segments, the junction between scarred and normal muscle is not as clearly defined as in dyskinetic aneurysms. Through the open ventricle, the fibrous endocardial scar determines the border zone between the totally fibrous tissue and the beginning of muscular tissue. With ventricular arrhythmia, the endocardial scar is mobilized and resected, and cryotherapy is applied to the edge of the resection.

An endoventricular circular suture as described by Fontan is placed with a 2-0 Prolene monofilament suture (Ethicon, Inc., Somerville, N.J.) to restore the "neck" of the contracting ventricle to be retained and thereby provide a more normal oval curvature of the ventricle. The circular suture is passed in the fibrous tissue above the transitional zone between normal and scarred tissue to construct the "artificial neck" that will be closed with a Dacron patch or autologous endocardial tissue. With endocardiectomy, this suture leaves within the ventricular cavity a region of 1 or $2 \mathrm{~cm}$ of open surface without endocardium. The patch that is used to rebuild the ventricle is tailored to the dimensions of the new artificial neck in both vertical and horizontal diameters. Conversely, the hemicircular autologous patch, modeled from septal scar with a septal hinge, can be used to close the "artificial neck" and restore the circularity of the cavity. The area excluded includes almost half of the septum and the posterior wall up to the root of the posterior papillary muscle. After closure, the excluded external tissue is folded to reinforce the suture line. Direct suture of the septum is avoided to protect the revascularized left anterior descending coronary artery.

Statistical analysis. All data are expressed as mean \pm standard error. Univariate screening between patients with akinetic and dyskinetic scar consisted in analyzing the significance of the difference of means of continu- 


\section{DYSKINETIC}

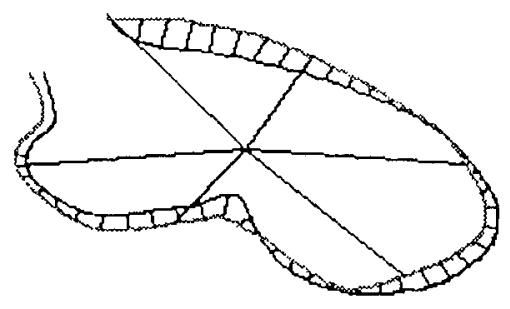

\section{E.F. $20 \%$}

$$
A \%=X / Y=65
$$

A

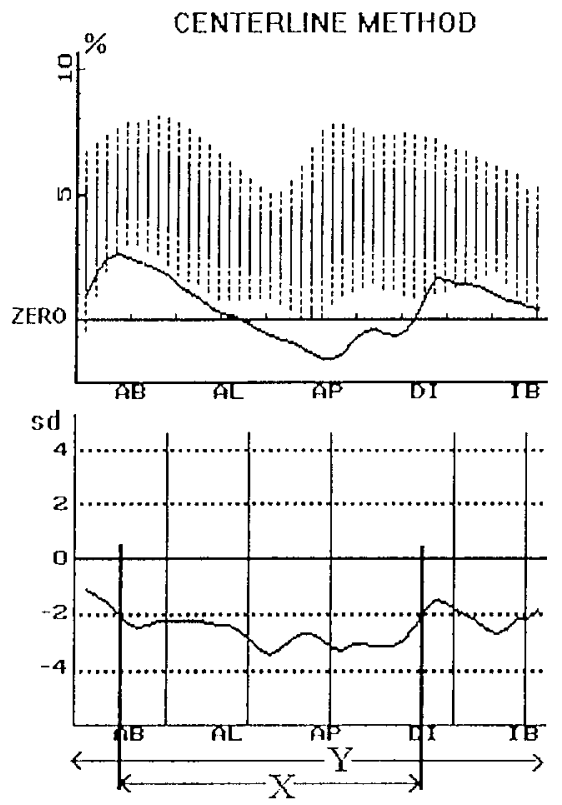

$$
\text { ASYNERGY EXTENSION }
$$

\section{AKINETIC}
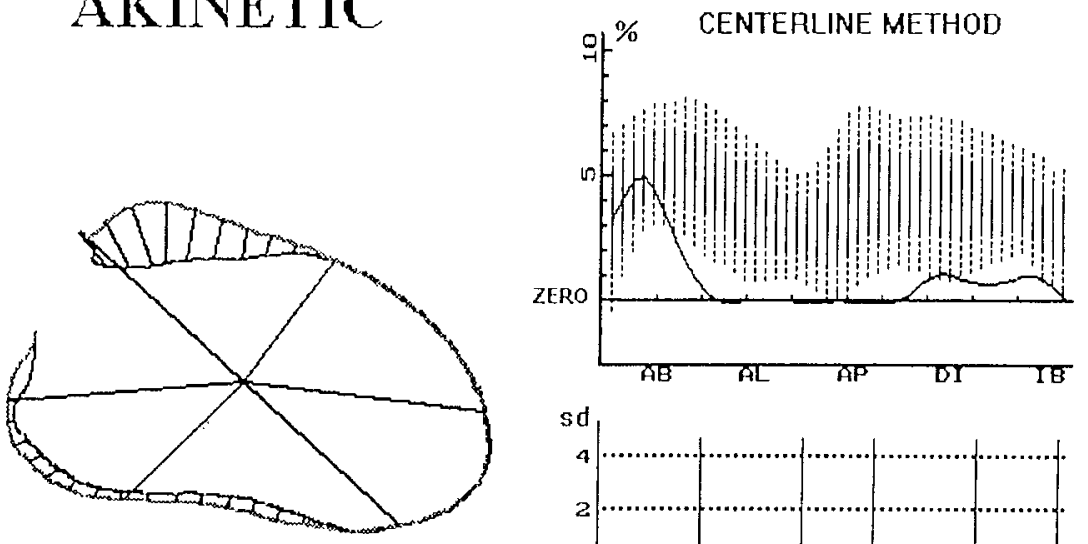

\section{E.F. $21 \%$}

$$
A \%=X / Y=85
$$

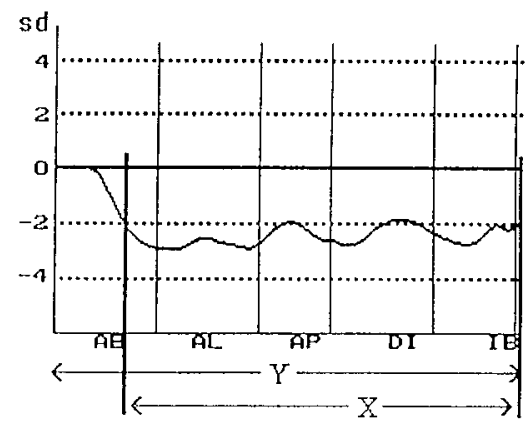

B

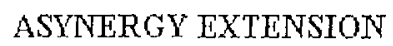

Fig. 1. Examples of preoperative centerline analysis in dyskinetic (A) and akinetic (B) LV aneurysms. Vertical lines indicate the extent of asynergy. E.F., Ejection fraction; $A B$, Anterobasal; $A L$, anterolateral; $A P$, apical; $D I$, diaphragmatic; $I B$, inferobasal.

ous variables ( $t$ test) or distribution of dichotomous variables $\left(\chi^{2}\right.$ test or Fisher exact test) or, when the data were not normally distributed, by nonparametric tests (McNemar test, Friedman test). Analysis of variance by repeated measures followed by comparison by means of
Bonferroni correction has been performed to analyze differences within groups; the unpaired $t$ test was used to analyze differences among groups. ${ }^{14}$ The survival curve was established by the life table analysis method. ${ }^{15}$ 


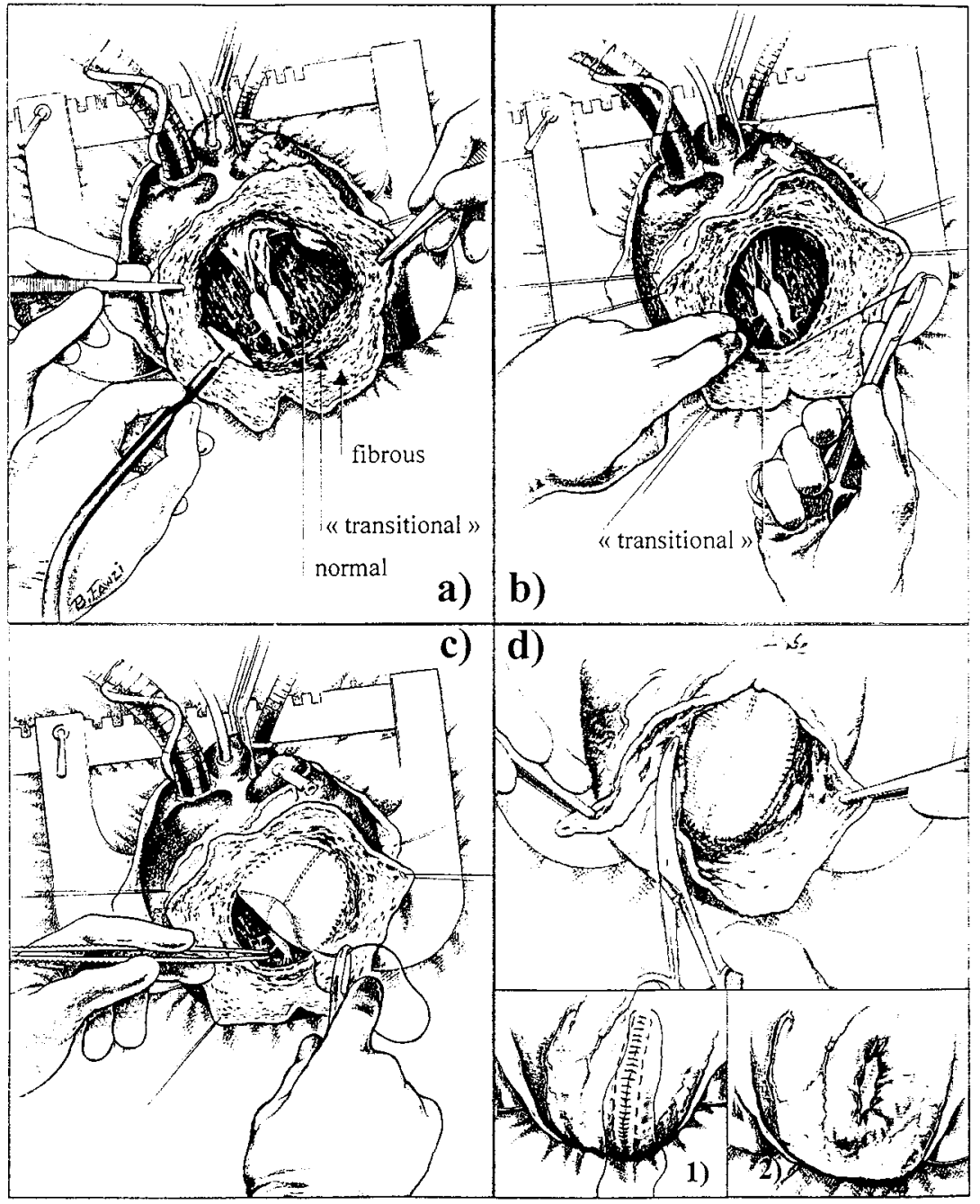

Fig. 2. LV remodeling for a large area of scarred postinfarction anterior myocardium. a, The opening of the LV and cryotherapy at the junction between fibrotic and normal endocardium. $\mathbf{b}$, The endoventricular continuous suture with 2-0 monofilament is shown in the intermediate (transitional) zone between normal and totally fibrous tissue to create an artificial neck. Following this, $\mathbf{c}$ shows the Dacron patch anchored with the same 2-0 filament suture. After placement of the EVCPP (d), there is resection of exteriorized fibrous tissue and suture (1) or folding (2) above the patch without stitches. This management of the endoventricular group avoids distortion of the right ventricle.

\section{Results}

Preoperative clinical data are shown in Table I. Most patients had two- or three-vessel coronary disease; the left anterior descending artery was occluded or significantly narrowed in all but one patient, in whom a patent left anterior artery may reflect a recanalized thrombosis. The scar was repaired with a synthetic patch in 30 of 51 patients with akinetic scars and in 34 of 49 patients with dyskinetic scars. An autologous patch was used in the remaining patients. The mean aortic crossclamp time was similar in the two groups $(73 \pm 23$ and $72 \pm 18$ minutes, respectively). Cryotherapy was initiated in 1989 and used in 47 patients (24 with akinetic and 23 with dyskinetic scar); five patients in 1987 and 1988 did not undergo cryotherapy because of its unavailability for ventricular arrhythmias. Myocardial revascularization was performed in 98 of 100 patients $(98 \%)$. The left or right internal thoracic artery was used in $84 \%(84 / 100)$, and 62 of 100 
Table I. Preoperative findings in the study group

\begin{tabular}{lcc}
\hline & $\begin{array}{c}\text { Akinetic } \\
(51 \text { patients) }\end{array}$ & $\begin{array}{c}\text { Dyskinetic } \\
\text { (49 patients) }\end{array}$ \\
\hline Age (yr) & $60 \pm 1.2$ & $61 \pm 1.5$ \\
Male/female & $48 / 3$ & $44 / 5$ \\
Delay from MI (mo) & $48 \pm 8.7$ & $37 \pm 8.4$ \\
Angina & & \\
$\quad$ Yes & $23(45 \%)$ & $24(49 \%)$ \\
$\quad$ No & $28(55 \%)$ & $25(51 \%)$ \\
Operation on emergency basis & $10(20)$ & $13(26)$ \\
Mitral regurgitation & $21(41)$ & $14(29)$ \\
NYHA class & & \\
$\quad$ I-II & $12(24 \%)$ & $13(27 \%)$ \\
$\quad$ III-IV & $39(76 \%)$ & $36(73 \%)$ \\
Spontaneous VT & $9(17 \%)$ & $11(22 \%)$ \\
Inducible VT & $15 / 33(45 \%)$ & $17 / 34(50 \%)$ \\
Noninducible VT & $18 / 33(55 \%)$ & $17 / 34(50 \%)$ \\
Extent of CAD & & \\
$\quad$ One vessel & $13(25 \%)$ & $11(22 \%)$ \\
$\quad$ Two vessels & $23(46 \%)$ & $21(43 \%)$ \\
$\quad$ Three vessels & $15(29 \%)$ & $16(33 \%)$ \\
$\quad$ Left main & $3(6 \%)$ & $4(8 \%)$ \\
Coronary score & $8 \pm 0.4$ & $7 \pm 0.4$ \\
Preoperative IABP & $8(16 \%)$ & $10(20 \%)$ \\
\hline
\end{tabular}

$M I$, Myocardial infarction; NYHA, New York Heart Association; VT, ventricular tachycardia; $C A D$, coronary artery disease; $I A B P$, intraaortic balloon pumping. Figures indicate number of patients unless otherwise indicated.

patients had saphenous vein grafts. The mean number of bypass grafts was $2.1 \pm 0.5$ per patient. The territory of the scar was revascularized in 44 of 51 $(86 \%)$ patients with akinetic scar and in 47 of 49 (96\%) with dyskinetic scar. Ten patients (five with akinesia and five with dyskinesia) had mitral valve repair or replacement.

The in-hospital mortality was $12 \%$ (12/100). Five patients in the akinetic group died $(10 \%)$ and seven in the dyskinetic group (14\%). Mean EF of patients who died was $22 \% \pm 1.6 \%$ versus $23 \% \pm 0.6 \%$ in survivors.

Table II records hemodynamic data in the preoperative and postoperative periods and 1 year after the operation. No significant differences occurred between the two groups for basal measures at univariate variance analysis. In all patients, postoperative EF rose and early capillary wedge pressure fell. The early fall in pulmonary pressure was significant only in the dyskinetic group. Additionally, end-diastolic and end-systolic volumes fell significantly in the dyskinetic group. The early postoperative ventricular volume remained significantly higher in patients with akinesiac versus those with dyskinesia. One year after the operation, systolic and diastolic ventricular volumes and pulmonary pressures were higher than the early postoperative values in both groups.

Fig. 3 shows mean pulmonary pressure before and after the operation in individual patients with akinesia and indicates no statistical difference at 1 year. Many patients (45\%) had preoperative moderate to severe pulmonary hypertension, but only nine patients $(18 \%)$ had severe pulmonary hypertension 1 year after the operation.

Table III reports preoperative and postoperative spontaneous and inducible arrhythmias by group and documents the infrequent occurrence in only three patients at 1 year.

Fig. 4 shows survival curves and includes operative mortality. The difference between groups is not significant. Nineteen late deaths occurred in the overall population. Of these 19 deaths, 13 were in the akinetic group. Causes of death were congestive heart failure in five patients, noncardiac causes in four, unknown in three, and sudden death in one. Six patients died in the dyskinetic group: congestive heart failure in three, unknown cause in two, and late sudden death in one. One patient in the akinetic group had heart transplantation 19 months after the operation and now awaits a renal transplant 4 years after the operation. Twenty-nine (29) surviving patients with akinetic scar and 28 with dyskinetic scar are in New York Heart Association class I-II, three in each group are in class III, and one (with dyskinesia) is in class IV.

\section{Discussion}

We will not repeat our prior descriptions of the efficacy of surgical procedures for postinfarction aneurysm. ${ }^{16}$ The central theme of our approach for ventricular reconstruction is to lower LV volume by excluding the nonresectable septum. Reconstruction is added to revascularization and cryotherapy, when indicated. We report that standard application of EVCPP caused some improvement in EF (24\% to $42 \%$ ) in patients with large postinfarction akinetic or dyskinetic scar.

The extent of asynergy and LV remodeling. Klein, Herman, and Gorlin ${ }^{17}$ showed that when the infarcted scar exceeds $20 \%$ of the LV surface area, cardiac function begins to decline whether the scar bulges or not. They hypothesized, and we agree, that there is a continuum between pure dyskinesia and pure akinesia. Both dyskinetic and akinetic scars share the identical mechanical defect of asynchronous and nonuniform global contraction that starts at the border zone because of fibrous or necrotic 
Table II. Preoperative and postoperative hemodynamic data

\begin{tabular}{|c|c|c|c|c|c|c|}
\hline & \multicolumn{3}{|c|}{ Akinetic } & \multicolumn{3}{|c|}{ Dyskinetic } \\
\hline & $\begin{array}{c}\text { Preop } \\
(n=51)\end{array}$ & $\begin{array}{c}\text { Postop } \\
(n=46)\end{array}$ & $\begin{array}{l}\text { One year } \\
(n=20)\end{array}$ & $\begin{array}{c}\text { Preop } \\
(n=49)\end{array}$ & $\begin{array}{c}\text { Postop } \\
(n=42)\end{array}$ & $\begin{array}{l}\text { One year } \\
(n=29)\end{array}$ \\
\hline $\mathrm{EF}(\%)$ & $23 \pm 0.8$ & $38 \pm 1.7^{*}$ & $40 \pm 4.0$ & $23 \pm 0.7$ & $41 \pm 1.9^{*}$ & $41 \pm 2.6$ \\
\hline $\operatorname{EFc}(\%)$ & $33 \pm 1.7$ & & & $38 \pm 1.8$ & & \\
\hline $\operatorname{EDVI}\left(\mathrm{ml} / \mathrm{m}^{2}\right)$ & $246 \pm 11$ & $105 \pm 7.9 \dagger$ & $127 \pm 14 \dagger \ddagger$ & $205 \pm 12$ & $80 \pm 4.0^{*}$ & $97 \pm 5 \ddagger$ \\
\hline $\operatorname{ESVI}\left(\mathrm{ml} / \mathrm{m}^{2}\right)$ & $188 \pm 9.8$ & $70 \pm 6.3^{*}+$ & $80 \pm 12 \dagger \ddagger$ & $160 \pm 10$ & $48 \pm 2.9^{*}$ & $58 \pm 5 \ddagger$ \\
\hline $\mathrm{CI}\left(\mathrm{L} / \mathrm{min} / \mathrm{m}^{2}\right)$ & $2.6 \pm 0.09$ & $2.6 \pm 0.1$ & $2.7 \pm 0.1$ & $2.5 \pm 0.09$ & $2.6 \pm 0.1$ & $2.6 \pm 0.1$ \\
\hline $\mathrm{PAP}(\mathrm{mm} \mathrm{Hg})$ & $27 \pm 1.5$ & $22 \pm 1.5$ & $36 \pm 5.5 \ddagger$ & $24 \pm 1.8$ & $19 \pm 1.2^{*}$ & $30 \pm 3.4 \ddagger$ \\
\hline $\mathrm{CW}(\mathrm{mm} \mathrm{Hg})$ & $19 \pm 1.3$ & $13 \pm 1.2^{*}$ & $23 \pm 4.7$ & $16 \pm 1.3$ & $12 \pm 0.9^{*}$ & $19 \pm 2.6$ \\
\hline
\end{tabular}

$E F$, Ejection fraction; $E F c$, contractility ejection fraction; $E D V I$, end-diastolic volume index; $E S V I$, end-systolic volume index; $C I$, cardiac index; $P A P$, pulmonary artery pressure; $C W P$, capillary wedge pressure.

${ }^{*} p<0.05$ versus basal.

$\dagger p<0.05$ versus dyskinetic.

$\ddagger p<0.05$ postop versus 1 year.

and rigid tissue where the scar joins more normal muscle. This produces an abnormal wall stress and a "temporal continuum." "18, 19 The "passage" from one shape to another may be due to progressive ventricular remodeling with the loss of internal bending at the border zone causing severe regional dysfunction. ${ }^{18,19}$

Alternatively, epicardial muscle salvaged by percutaneous transluminal coronary angioplasty or thrombolysis may prevent dyskinetic scar formation and lead to akinesia. We found that regional contraction remote from anterior infarct zones may be poorer in akinetic than in dyskinetic scar. Patients with akinetic scar had worse (although not significantly worse) basal hemodynamics, higher volumes and right-sided pressures, and slightly longer delay from infarction to correction (37 vs 48 months).

Others suggest the definition and classification of these two types of scar may be difficult and qualitative, even with the centerline method, if ejection is depressed. Each patient had a considerable asynergy $(\mathrm{A} \%>60)$ that was far above the $20 \%$ reported by Gorlin. We recognize that $\mathrm{A} \%$ is not a measure of the size of the scar per se, but a measure of the extent of asynergy or noncontraction. The progression from dilatation to dysfunction is multifactorial and may be progressive. ${ }^{19,20}$

Our patients with end-stage dilatation and severe dysfunction also had angina, symptoms of congestive failure, and a high incidence of ventricular arrhythmias. Each event identifies increased risk of early mortality. We are inclined to recommend early repair to postpone ongoing regional dysfunction because of our knowledge that (1) the surgical risk for ventricular repair is
Table III. Ventricular arrhythmias in the study group

\begin{tabular}{lrrrrrrrr}
\hline & \multicolumn{3}{c}{ Akinetic } & & \multicolumn{4}{c}{ Dyskinetic } \\
\cline { 2 - 4 } \cline { 7 - 9 } & Preop & Postop & One year & Preop & Postop & One year \\
\hline Spontaneous VT & 9 & 1 & - & & 11 & 1 & - \\
Inducible VT & 15 & 7 & 2 & & 17 & 2 & 1 \\
Noninducible VT & 18 & 31 & 18 & & 17 & 30 & 23 \\
Total PVS & 33 & 39 & 20 & & 34 & 32 & 24 \\
Contraindicated & 14 & 1 & - & 7 & 1 & - \\
\hline
\end{tabular}

$V T$, Ventricular tachycardia; $P V S$, programmed ventricular stimulation.

relatively low so long as EF is greater than $30 \% ; 4,20,21$ (2) contractile function of remote muscle may deteriorate progressively, ${ }^{22,23}$ possibly because of ischemic cardiomyopathy; and (3) significant improvement in contractile function of remote muscle occurs immediately after EVCPP.

Currently, this concept is not shared by clinicians or surgeons, ${ }^{24}$ and surgical therapy is restricted to patients with severe dilatation and dysfunction many years after infarction. This may be especially true in patients with large akinetic scar, because uncertainties exist about surgical outcome and survival. ${ }^{25,26}$ Some authors ${ }^{27}$ who use a linear surgical suture approach found a strong correlation between the degree of paradoxic movement of an aneurysm and improvement in EF. They observed no improvement in akinetic scars. Our results with EVCPP disagree completely with this concept. Our data indicate that similar improvement in EF (23\% to $42 \%)$ in akinetic and dyskinetic scar occurs only when ventricular repair excludes the nonresectable septum.

The contrast between dyskinesia and akinesia is artificial, because neither segment contracts. We 


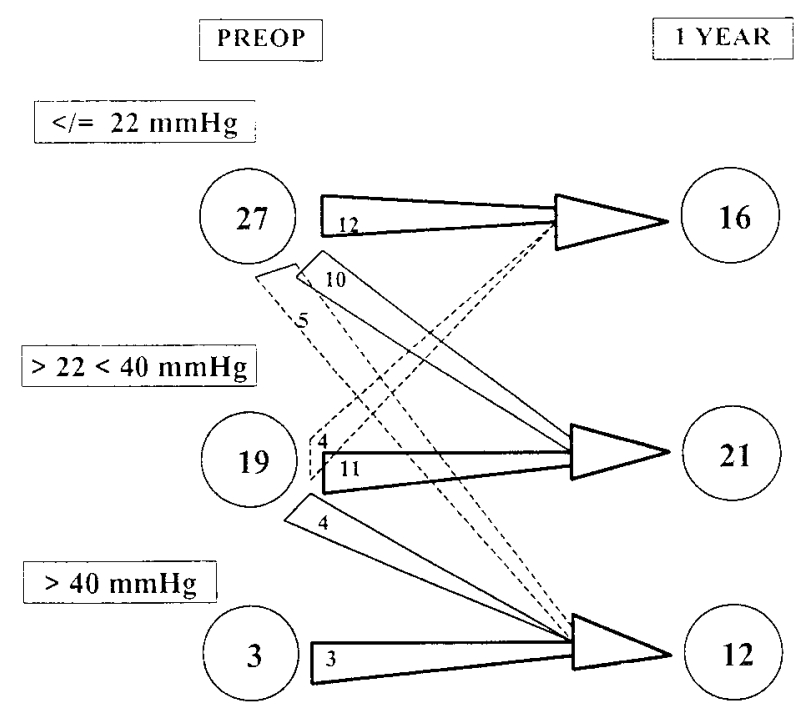

Fig. 3. Mean pulmonary artery pressure in individual patients with akinetic scar who underwent hemodynamic study 1 year after the operation, divided according to preoperative values. Note that some patients had severe pulmonary hypertension 1 year after the operation.

believe in the importance of the amount of asynergic zones, how they are excluded, and how the noninfarcted muscle is analyzed and revascularized to improve global function after the operation. This remote zone can reduce its contractility progressively because of ischemic cardiomyopathy. This was demonstrated clearly by Di Donato and coworkers ${ }^{18}$ who showed reduced remote muscle function to precede development of heart failure. In endstage ischemic cardiomyopathy, we specifically analyze function in remaining remote areas because they can malfunction despite normal coronary arteries, especially if they are also ischemic.

Advantages of patch plasty. The concept of EVCPP and geometric reconstruction is now more fully understood. Its major advantages include the following: (1) allowing for exclusion of the nonresectable scarred areas in the septum, which cannot occur with the standard linear suture; (2) using an intraventricular patch to redirect normal muscle bundles toward their original orientation and position, as described by Sosa and colleagues $^{28}$; (3) reducing ventricular cavity size; and (4) grafting infarct territory and remote muscle to try to improve contractility and reduce arrhythmias. Ventricular repair is technically more difficult in the akinetic heart, in which the shape is abnormally altered and global function is very depressed. These changes develop because the limit

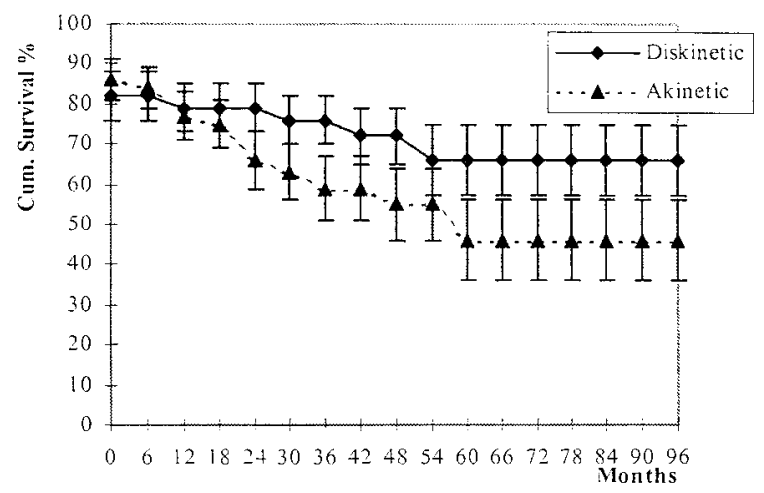

Fig. 4. Life table analysis of the two groups, including operative mortality, is shown. The difference between the two groups was not significant according to Wilcoxon statistics. Numbers in the abscissa indicate months.

between scar and normal tissue is not clearly defined when the trabecular scar is not circumferential. Consequently, the placement of the patch is left to the surgeon's judgment. If placed too high, the patch may produce a smaller residual cavity that can worsen LV diastolic function.

On follow-up at 1 year, we observed an increase in LV volumes that was significant in both groups. This increase may be due to (1) continued LV remodeling, (2) further evolution of coronary artery disease or repeated ischemic episodes, (3) evolving scar or muscle dilatation not present or at least not recognizable before the operation, or (4) improper identification of the transition between scar and normal muscle in akinetic regions, leading to possible salvage of an excess of scarred ventricle.

The late increase in mean pulmonary pressure has resulted in showing no difference from the preoperative values at 1 year, because many patients (45\%) had preoperative pulmonary hypertension (Fig. 3) and only four patients (18\%) had severe pulmonary hypertension 1 year later. One possible mechanism for this rise in pressure is a reduction of $\mathrm{LV}$ chamber compliance by surgical reshaping, despite the reduction in LV volume resulting from EVCPP.

We recognize that late unsatisfactory functional results occurred in some patients, and therefore we compared EVCPP for the treatment of ischemic or akinetic scars with other possible techniques: The Batista technique includes resection of the normally perfused free lateral wall of the LV to reduce its volume. This procedure is predominantly used for dilated cardiomyopathies. In patients with ischemic anterior scar, the lateral wall is nonischemic and not 
fibrous and should not be resected. In contrast, we used remodeling by the EVCPP technique ${ }^{29}$ to exclude the septum. Both techniques ensure reduced radius, in keeping with Laplace's law, but differ in regard to the septum, which is kept in the Batista procedure and excluded with the EVCPP technique.

Cardiomyoplasty prevents further dilation but does not reduce the size of the chamber. It does not produce good immediate and late results in large postinfarction dyskinetic or akinetic ventricles, especially in patients in New York Heart Association class IV, as reported by Carpentier and coworkers. ${ }^{30}$ Preoperative dilation of the LV beyond $300 \mathrm{ml}$, pulmonary hypertension, and ventricular arrhythmias are contraindications to cardiomyoplasty. Each of these occurred frequently among our patients treated with EVCPP.

Cardiac transplantation, in theory, is much more logical. It is more radical, despite a simpler immediate preoperative and postoperative course. In practice, transplantation is somewhat uncommon because of (1) the reduced donor/need ratio and (2) the fact that many patients with advanced age, pulmonary hypertension, renal insufficiency, and diabetes have unsatisfactory late results. Our immediate data of improved EF at 1 year suggest that heart transplantation should be reserved until after reconstructive conservative methods are attempted.

In conclusion, ventricular repair by EVCPP, associated with coronary grafting and cryotherapy (when indicated), improved hemodynamic function and clinical status in surviving patients with large postinfarction scar and severe LV dysfunction. Long-term follow-up shows a higher late mortality in patients with akinetic scar who undergo EVCPP than in those with dyskinetic scar, but the difference is not significant. Long-term studies will show whether earlier "remodeling" by surgical repair after infarction can prevent progression toward end-stage disease. We suspect it will lead to even further improvement in symptoms and long-term survival.

\section{REFERENCES}

1. Swan JC. Left ventricular systolic and diastolic dysfunction in the acute phases of myocardial ischemia and infarction, and in the later phases of recovery: function follows morphology. Eur Heart J 1993;14(suppl A):48-56.

2. Dor V, Kreitmann P, Jourdan J, et al. Interest of physiological closure (circumferential plasty on contractive areas) of left ventricle after resection and endocardiectomy for aneurysm or akinetic zone. Comparison with classical technique about a series of 209 left ventricular resections [abstract]. J Cardiovasc Surg 1985;26.

3. Di Donato M, Barletta G, Maioli M, et al. Early hemodynamic results of left ventricular reconstructive surgery for anterior wall left ventricular aneurysm. Am J Cardiol 1992; 69:886-90.

4. Grossi EA, Chinitz LA, Galloway AC, Delianides J, Schwartz DS, McLoughlin DE, et al. Endoventricular remodeling of left ventricular aneurysm: functional, clinical and electrophysiological results. Circulation 1995;92(Suppl):I198-100.

5. Everson CT, Hockmuth DR. Technical advances in the treatment of left ventricular aneurysm. Ann Thorac Surg 1993;55:792-800.

6. Couper GS, Bunton RW, Birjiniuk V, et al. Relative risks of left ventricular aneurysmectomy in patients with akinetic scars versus true dyskinetic aneurysms. Circulation 1990; 82(Suppl):IV248-56.

7. Di Donato M, Sabatier M, Dor V, Toso A, Maioli M. Fantini F. Akinetic versus dyskinetic postinfarction scar: relation to surgical outcome in patients undergoing endoventricular circular patch plasty repair. J Am Coll Cardiol 1997;29:156975.

8. Di Donato M, Sabatier M, Montiglio F, et al. Outcome of left ventricular aneurysmectomy with patch repair in patients with severely depressed pump function. Am J Cardiol 1995; 76:557-61.

9. Sheehan FH, Bolson EL, Dodge HT, Mathey DG, Shofer J, Woo HW. Advantages and applications of the centerline method for characterizing regional ventricular function. Circulation 1986;74:293-305.

10. Chapman CB, Baker O, Reynolds J, Bonte FJ. Use of biplane cinefluorography for measurement of ventricular volume. Circulation 1958;18:1105-17.

11. Louagie Y, Alouini T, Lesperance J, Pelletier LC. Left ventricular aneurysm with predominating congestive heart failure: a comparative study of medical and surgical treatment. J Thorac Cardiovasc Surg 1987;94:571-81.

12. Califf RM, Phillips HR, Hindman MC, et al. Prognostic value of coronary jeopardy score. J Am Coll Cardiol 1985;5:1055.

13. Dor V, Sabatier M, Montiglio F, Rossi P, Toso A, Di Donato M. Results of non guided subtotal endocardiectomy associated with left ventricular reconstruction in patients with ischemic ventricular arrhythmias. J Thorac Cardiovasc Surg 1994;107:1301-8.

14. Norusis MJ. SPSS for windows. Advanced statistics, Release 6.0. Chicago: SPSS Inc.

15. Grunkemeier GL, Starr A. Actuarial analysis of surgical results: rationale and method. Ann Thorac Surg 1977;24: 404-8.

16. Mills NL, Everson CT, Hockmuth DR. Technical advances in the treatment of left ventricular aneurysm. Ann Thorac Surg 1993;55:792-800.

17. Klein MD, Herman MV, Gorlin R. A hemodynamic study of LV aneurysm. Circulation 1967;35:614-30.

18. Di Donato M, Sabatier M, Toso A, et al. Regional myocardial performance of non-ischaemic zones remote from anterior wall left ventricular aneurysm: effects of aneurysmectomy. Eur Heart J 1995;16:1285-92.

19. Gaudron P, Eilles C, Kugler I, Erth G. Progressive left ventricular dysfunction and remodeling after myocardial infarction: potential mechanisms and early predictors. Circulation 1993;87:755-62. 
20. Colthrap WH, Hoff SJ, Stoney WS, et al. Ventricular aneurysmectomy: a 25 year experience. Ann Surg 1994;219:70714.

21. Dor V, Sabatier M, Di Donato M, Maioli M, Toso A, Montiglio F. Late hemodynamic results after left ventricular patch repair associated with coronary grafting in patients with postinfarction akinetic or dyskinetic aneurysm of the left ventricle. J Thorac Cardiovasc Surg 1995;110:1291-301.

22. McKay RG, Pfeffer MA, Pasternak RC, et al. Left ventricular remodeling after myocardial infarction: a corollary to infarct expansion. Circulation 1986;74:693-702.

23. Pfeffer MA, Braunwald E. Ventricular remodeling after myocardial infarction: experimental observations and clinical implications. Circulation 1990;81:1161-72.

24. Cohen M, Packer M, Gorlin R. Indications for left ventricular aneurysmectomy. Circulation 1983;67:717-22.

25. Burton NA, Stinson EB, Oyer PE, Shumway NE. Left ventricular aneurysm: postoperative risk factors and longterm postoperative results. J Thorac Cardiovasc Surg 1979; 77:65-75.

26. Sesto M, Schwartz F, Thiedemann KV, Flameng W, Schlepper M. Failure of aneurysmectomy to improve left ventricular function. Br Heart J 1989;47:746-51.

27. Mangaschau A. Akinetic versus dyskinetic left ventricular aneurysms diagnosed by gated scintigraphy: difference in surgical outcome. Ann Thorac Surg 1989;47:746-51.

28. Sosa E, Jatene A, Kaeriyama JV, et al. Recurrent ventricular tachycardia associated with postinfarction aneurysm. J Thorac Cardiovasc Surg 1992;103:855-60.

29. Replogle RL, Kaiser GC. Left ventricular reduction surgery. Ann Thorac Surg 1997;63:909-10.

30. Carpentier A, Chachques KC, Acar C, Relland J, Mihaileanu $\mathrm{S}$, Benasson D, et al. Dynamic cardiomyoplasty at seven years. J Thorac Cardiovasc Surg 1993;106:42-54.

\section{Discussion}

Dr. Michael K. Pasque (St. Louis, Mo.). In attempting to understand the clinical relevance of this excellent presentation, one must understand what exactly differentiates the two groups of patients who underwent EVCPP in this important study.

The key feature that discriminates the patient with a dyskinetic versus an akinetic postinfarction segment is decidedly not the mechanical function of the infarcted segment. The infarcted segment, whether dyskinetic or akinetic, is dead and contributes nothing during systole. Instead, the key discriminating feature between these two groups of patients is the mechanical activity of the immediately adjacent noninfarcted ventricular wall segments. The systolic function of these adjacent wall segments, often referred to as border zones, is preserved and readily differentiated from the infarcted segment in the patients defined as having dyskinetic scar. In contrast, the patients with akinetic scar have thinned, remodeled, and hypocontractile border zones that blend in with the infarcted segment.

These patients with akinetic scar typically have very poor ventricular function. When these patients are referred to our heart failure service, they are placed on aggressive tailored unloading therapy and their ventricular function is reassessed after an appropriate interval. Currently, if a significant improvement in the nonin- farcted wall segments is not seen, these patients usually are placed on our transplant list. This report clearly suggests that we can safely extend surgical repair to more of these patients. The EVCPP repair is ideal in this regard, because it respects the fact that ventricular geometry has three dimensions and that all three contribute to global ventricular functional recovery, including the ventricular long-axis dimension that was previously ignored by the classic longitudinal repair.

The true significance of this presentation, however, may be in its further illustration of the importance of ventricular wall stress. Simply defined, wall stress is a description of load distributed over myocardial wall volume. It is directly proportional to the diameter of the ventricular chamber. Wall stress is that fundamental physiologic parameter that explains the improvement in ventricular function seen after mitral valve repair in patients with dilated cardiomyopathy, and that explains promising early results after the Batista partial left ventriculectomy in the exact patients with end-stage heart failure whom we would intuitively predict are in need of all of the myocardium that they can muster. Of course, it also explains the excellent surgical results reported by Dr. Dor and his colleagues. Although our understanding of these phenomena is incomplete, fundamental to the physiologic explanation for these unlikely successes is their ability to reduce ventricular wall stress.

It is easy to recognize that, by definition, a dilated ventricle has higher wall stress. What is less easily understood is that this higher wall stress deleteriously afterloads the ventricle at every definable point throughout systole. It is not intuitive to think of the dilated ventricle as afterloaded, but at the contractile protein level, this is exactly the case. In terms of ventricular wall stress, the dilated ventricle, which characterizes the patients reported by Dr. Dor, is no different from the highly afterloaded ventricle found in the patient with aortic stenosis. Both ventricles have high systolic wall stress and high afterload. Both ventricles will have decreased wall stress when their respective, completely different operations are complete. Likewise, in both cases systolic ejection will be directly unloaded and both ventricles will contract better. This fundamental physiologic point is redefining our approach to patients with compromised ventricular function.

In this regard, I would like to ask Dr. Dor to compare the use of his procedure in this high-risk patient population to the use of the Batista partial left ventriculectomy in patients with dilated idiopathic cardiomyopathy. From a technical standpoint, I would like to hear his comments regarding the art of estimating residual chamber size when he is determining patch suture line placement in ventricles with no clear demarcation between infarcted segment and viable myocardium.

Dr. Lynda L. Mickleborough (Toronto, Ontario, Cana$d a$ ). Our experience in Toronto is very similar. We are also operating on a significant number of patients who have an LV aneurysm. In contrast, my American colleagues tell me that they rarely see a patient who requires aneurysm excision. I wonder if the difference in experience between Canada and Europe versus the United 
States is merely based on the difference in definition of an aneurysm.

We in Toronto agree with Dr. Dor that in patients with a large area of akinesia, not dyskinesia, resection and repair can lead to significant benefits not only in terms of LV function but also in terms of symptomatic improvement and benefits of survival. We have previously reported our results in such patients using a different technique, a modified linear closure technique.

I have one question for Dr. Dor. I agree with you that operating on these individuals earlier prevents them from getting into the end-stage situation where transplantation may be the only alternative; however, in doing so, it is often difficult to know whether an akinetic area will be better served by revascularization or excision. In your series, is your decision whether or not to resect the akinetic area always based on preoperative data or is the decision sometimes made in the operating room, taking into consideration intraoperative observations on thickness of the wall to be resected?

Dr. Dor. I thank my two colleagues for their comments. Dr. Pasque, as you mentioned, the importance of this reconstruction is the change in the wall stress in the remote area of the ventricle. In another article that we published in Circulation and the European Journal of Cardiology, we reported that the improvement occurs when you analyze the pressure-volume lengths chiefly on the remote segment of the dilated akinetic or dyskinetic area on the normal beating heart, which is improved dramatically after the operation. We have a great deal of documentation about this improvement because of the reorganization of the contractile area.

To answer Dr. Mickleborough's question, I wrote this paper chiefly to focus attention on the fact that not only aneurysm but also akinesia can be improved by this technique. Many cardiologists and surgeons are still following a foolish concept, saying that only pure aneurysms were partially improved because the surgeon left more than two thirds of the dyskinetic or unbeating area inside the ventricle. That foolish conclusion was based on 18 cases. Among them, six were followed up in the postoperative period. In this series it was a rule for cardiologists that it is not necessary to repair an aneurysm, because we were not improving hemodynamic function. That is not true, particularly when you use a patch sutured inside the ventricular uncontracted area, allowing it to bypass all diseased vessels around and rebuilding the normal cavity in a better way than can be done with the classic linear suture. You ask about prevention. It would be preferable to operate on the patient before the hemodynamic impairment develops when there is a large area of akinesia, even asymptomatic at rest, because with manometric tests it is possible to check the beginning of the impairment of the functional class.

Regarding the decision, you are right. In the majority of cases, if we ask the cardiologist to do a good echocardiographic analysis of the left and right ventricles, we can detect the septal akinesia and decide during revascularization to suppress this dyskinetic or akinetic area. However, sometimes the decision is made during the operation. We make a small opening in the apex, which seems normal, and if we check a large septal area which is fibrous, we do the repair by the simple technique of the autologous patch. This takes less than 20 minutes. Sometimes we are making the decision on the operating table, but it is rare. In the majority of cases the decision is made before the operation is begun.

\section{Availability of Journal back issues}

As a service to our subscribers, copies of back issues of The Journal of Thoracic and Cardiovascular Surgery for the preceding 5 years are maintained and are available for purchase from Mosby at a cost of $\$ 16.00$ per issue until inventory is depleted. The following quantity discounts are available: $25 \%$ off on quantities of 12 to 23, and one third off on quantities of 24 or more. Please write to Mosby, Inc., Subscription Services, 11830 Westline Industrial Drive, St. Louis MO 63146-3318, or call 800-453-4351 or 314-453-4351 for information on availability of particular issues. If unavailable from the publisher, photocopies of complete issues may be purchased from UMI, 300 N. Zeeb Rd., Ann Arbor, MI 48106, 313-761-4700. 